\title{
UNRAVELLING LEARNING ENGAGEMENT IN THE HYBRID VIRTUAL CLASSROOM
}

Annelies Raes, Pieter Vanneste, Marieke Pieters, Ine Windey, Wim Van Den Noortgate, Fien Depaepe, KU Leuven Kulak, Belgium

\section{Connecting learners and crossing borders through the hybrid virtual classroom}

Based on current societal transitions and in the context of lifelong learning, both upper secondary education, higher education and vocational training are invited to think about how to enable people, at any stage of their life, to take part in stimulating learning experiences. The expectancy to be present at one core location is getting more and more difficult in this (inter)national society. In addition, the student population is changing and balancing work and family life becomes an important point of priority. Therefore, it is important to make education less dependent on location and time and improve flexibility within the learning trajectory (Lakhal, De Sherbrooke, \& Bateman, 2017). Next to this, there are growing insights about the need to collaborate over the borders of the institution to implement expertise from partner organisations.

To deal with these shifts in education, a university project invested in the design, research and development of a hybrid virtual classroom, as displayed in Figure 1, in collaboration with two industry partners. This hybrid virtual classroom creates not only opportunities for on-campus face-to-face (F2F) learning, but also for connecting remote individuals synchronously, overcoming distance limitations to enable remote interactions between students and teachers and among students. All students have access to an interactive platform, allowing them to participate in the course, either on-site or from a remote location. The platform gives access to the sources the teacher is using during his lecture (e.g. power point slides or annotations made on the Wacom), the platform facilitates launching interactive quizzes and polls and a chat room is integrated which gives students to chat with each other during the lecture. 


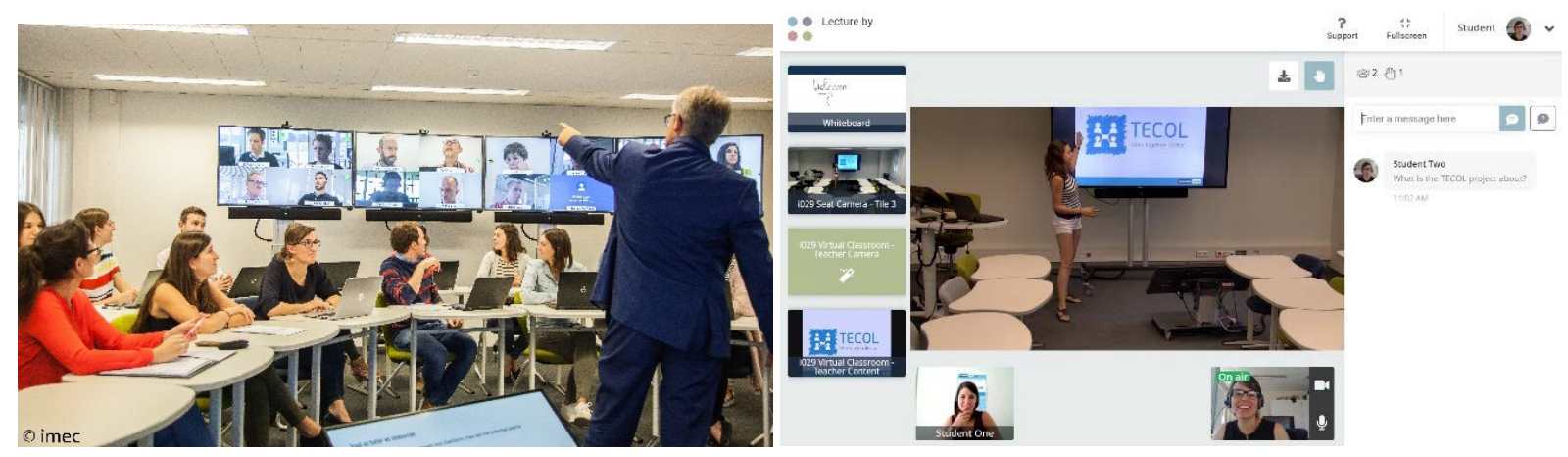

Figure 1. Left picture displays the hybrid virtual classroom including both F2F and remote individual students.

Right picture displays the platform visible for the students

\section{Engagement of remote students from a self-determination perspective}

Based on previous research literature, it is known that in case of synchronous hybrid learning, it gets more difficult to activate and engage the remote students to the same degree as the students attending F2F. In the study of Weitze (2015) for example, Global Classroom was investigated as an innovative synchronous hybrid videoconference concept, where adult students could choose between participating in class on campus or from home via videoconference. In this study both students and teachers stated in the questionnaires and in the interviews that - compared to students attending the lesson $\mathrm{F} 2 \mathrm{~F}$ - remote students learned less, were generally more passive and often behaved like they were watching TV and not attending a lesson. One of the reasons for this finding was that teachers gave classes according to more monologue-based teaching strategies, which are not well-suited for this kind of learning settings. Remote students also indicated that it was difficult to make the teacher aware that they wanted to answer a question, which made them feel frustrated and uninvolved, leading to a significant sense of distance from their institution, their teacher and their peers.

These low levels of engagement for remote students need to be taken seriously as student engagement is associated with positive learning outcomes (Fredricks, Blumenfeld, \& Paris, 2004). Based on previous research, we can state that engagement particularly involves three dimensions or components, (a) behavioural (e.g., focus, attention, participation, effort or involvement), (b) affective (parameters like interest, boredom, frustration or enjoyment), and (c) cognitive engagement (including learning outcomes, metacognition and self-regulated learning). This three-component model is displayed by the three circles in Figure 2 and has been used by several researchers in the past (e.g. Dobbins \& Denton, 2017; Gobert, Baker, \& Wixon, 2015).

In this study, we are particularly interested in unravelling the affective engagement which is the highlighted circle. We further operationalized affective engagement based on the selfdetermination theory (SDT; Deci \& Ryan, 1985). SDT has been established as a well-validated and coherent framework for the conceptualization and investigation of motivation in education (e.g. Raes \& Schellens, 2015; Vansteenkiste, Sierens, Soenens, Luyckx, \& Lens, 
2009), and provides theoretical grounds for examining how the social context of a learning environment can influence the motivation for one's learning experience. According to Deci and Ryan's SDT, motivation can be distributed along a continuum from low to high levels of self-determination. The most self-determined style of motivation is intrinsic motivation (IM) and as displayed in Figure 2, it is maintained that IM can be fostered when the context facilitates the satisfaction of three basic needs: students' need for autonomy, competence, and relatedness (Vansteenkiste et al., 2009).

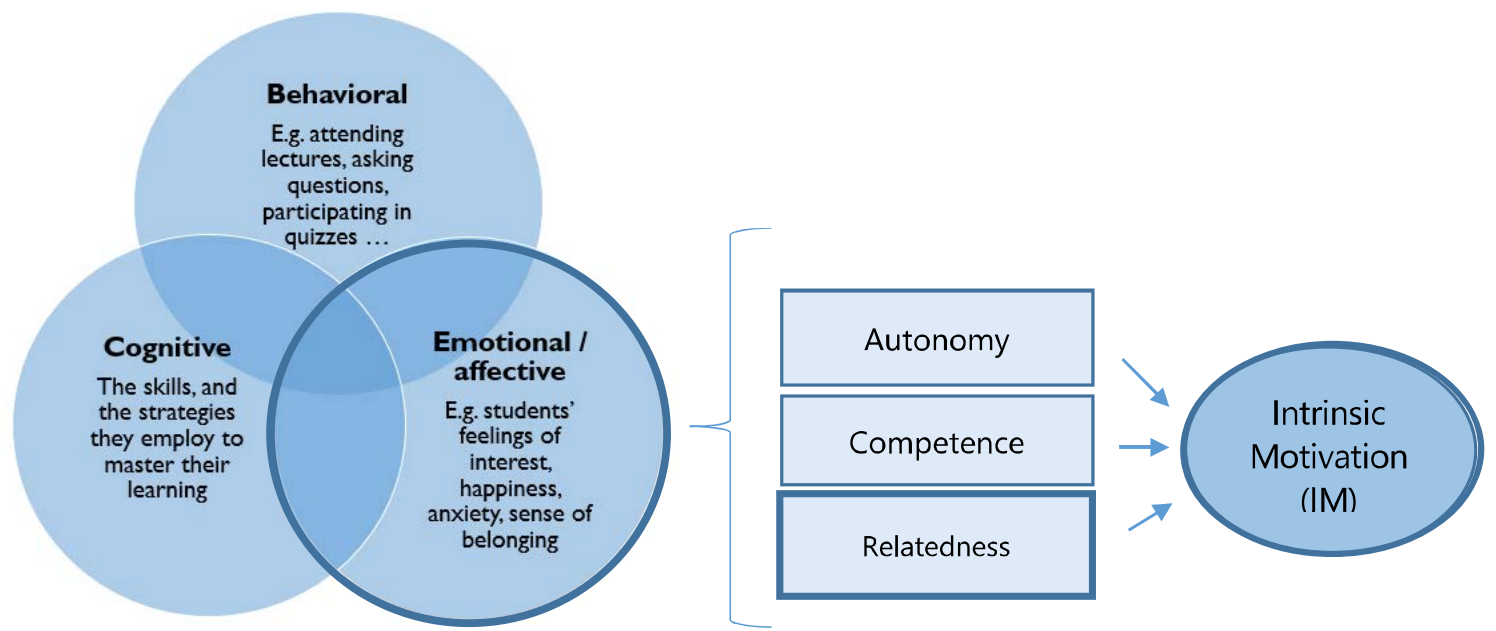

Figure 2. Aspects of student engagement within taught contexts (Dobbins \& Denton, 2017) and affective engagement perceived from the self-determination theory (Deci \& Ryan, 1985). The affective component and the basic need of relatedness are highlighted as these constructs represent the main focus of this study.

\section{Research scope \& methodology}

As stated before, the satisfaction of the need for relatedness can be problematic in the context of a hybrid virtual classroom, particularly for the remote students. Previous research has shown that remote learners feel a significant sense of distance from their institution which illuminates the need to address the perceived distance between remote students and their teachers and F2F classmates by establishing some sort of connectedness (Ramsey, Evans, \& Levy, 2016). Therefore, in this study we focus on how the basic need of relatedness is experienced by students in the hybrid virtual classroom and how this affects IM as proxy of students' affective engagement. Based on previous research it is hypothesized that the more related students feel with their peers and their teacher the better IM in learning is supported (Hutchinson, Lauckner, Meisner, Gallant, \& Silversides, 2017). Given the educational setting, it is hypothesized that students will be most motivated in the F2F setting and least motivated in the remote setting. Previous studies who investigate motivation in a hybrid virtual learning context comparing the experiences of F2F and remote students are limited and mostly based on qualitative methods (e.g. Weitze, 2015). This study aims to fill this research gap by systematically investigating both relatedness and IM in the hybrid virtual classroom through a quasi-experimental within subjects' design (see Figure 3) comparing three learning settings. We collaborated with one teacher of secondary education and his 14 students of Grade 12 (average age of 17) following the course "Economics". Four students were girls and ten were 
boys. During six consecutive courses (100 minutes per week), the teacher came to the University and taught his lecture in the hybrid virtual classroom. As displayed in Figure 3, during Lecture 1 and Lecture 2, all students followed the course F2F. In Lecture 3 and Lecture 4, the students participated in the hybrid setting, the student group was split up and half of the students were following the course virtually and half of the students were following F2F. The groups were swapped after Lecture 3, so all students could experience both perspectives in the hybrid classroom. In Lecture 5 and 6 all students followed the course virtually, whereas the teacher was present in the hybrid virtual classroom. As a result, four conditions can be distinguished: a pure face-to-face condition (F2F), a hybrid session followed face-to-face (hybrid-F2F), a hybrid session followed remotely (hybrid-remote) and a pure virtual condition (Virtual).

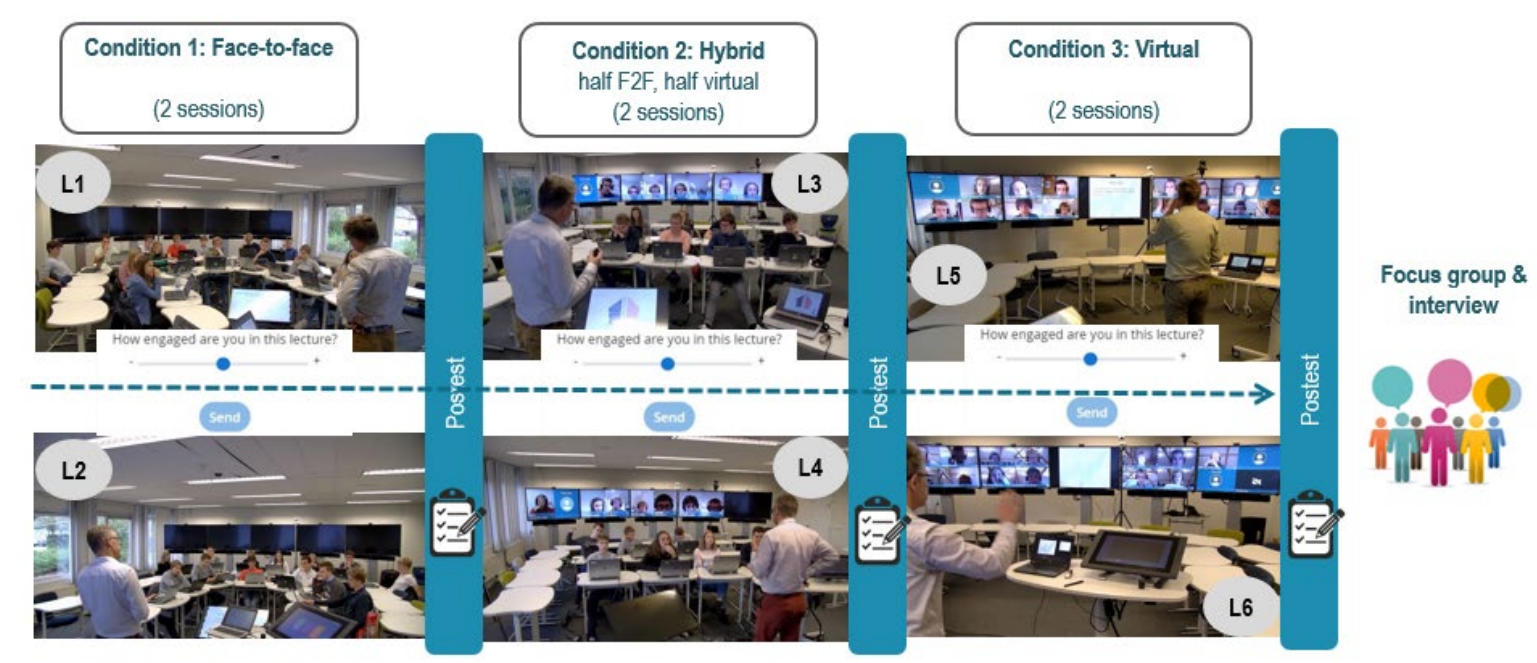

Figure 3. Quasi-experimental within-subjects design in which one teacher and 14 students were followed during six lectures

Data has been collected from a mixed methods approach (i.e., the combination of quantitative and qualitative research methods) as this strengthens the inferences in both processes and outcomes of data analysis (Cohen, Manion, \& Morrison, 2011).

Quantitative data consisted of a post-test survey administered four times: (a) after the two F2F sessions, (b) after the first hybrid session in which half of the students followed virtually, the other half F2F, (c) after the second hybrid session, (d) after the two virtual sessions. The post-test included existing scales of the Intrinsic Motivation Inventory (IMI) (Deci \&, Ryan, 1985) consisting of Likert-scale questions using six-point agreement levels from 1 - strongly disagree to 6 - strongly agree. The instrument assesses participants' interest/enjoyment, perceived competence, effort, value/usefulness, felt pressure and tension, perceived choice, and experience of relatedness during a certain activity, thus yielding seven subscale scores. In this study, we will only report on the relatedness scores and the scores for the interest/enjoyment subscale which is considered the self-report measure of IM. The perceived relatedness in this study is operationalized as relatedness towards peers (Rel_Peers) and 
relatedness towards teacher (Rel_Teacher) and these constructs are theorized to be positive predictors of self-report measures of intrinsic motivation (Niemiec \& Ryan, 2009).

The self-reports conducted at the end of each session have some shortcomings and biases as they are a snapshot articulation of engagement rather than an examination of how emotion unfolds in an interactive context (Scherer, 2005). Conducting self-reports only at the end of the course will result in a rather poor statistical power and does not allow to capture evolutions in engagement during the course. To counter this, a second measure of IM was added. During the six sessions, all students were registered on the platform and for the purpose of this study, we also build an engagement pop-up containing one question "How engaged are you now?" (displayed on Figure 3) which students could answer on a slider allowing for continuous variables. Students got this pop-up during all lectures at random intervals between 5 and 12 minutes.

Also qualitative data have been obtained through open-ended questions in the post-test, a semi-structured interview with the teacher and a semi-structured focus group with all students, one month after the last session. Both the interview and the focus group were audio recorded and fully transcribed afterwards. Based on the transcriptions, content analysis (Cohen, Manion, \& Morrison, 2011) was used to generate common experiences and valuable feedback regarding learning and teaching in the hybrid virtual classroom.

The results section includes the descriptive statistics and the main results of the qualitative analyses. In addition, the post-test data are analysed by using for each outcome variable separately a multilevel model containing fixed effects for the categorical independent variable (i.e., the educational setting). In our analysis four levels of the categorical classroom were distinguished as the hybrid condition included F2F and remote students: F2F, hybrid-F2F, hybrid-remote and Virtual. Students' effects are included as random effects to deal with the non-independence of a subject's residuals.

\section{Results}

Figure 4 presents the post-test results for the subscales IM (orange bars), Rel_Peers (green bars) and Rel_Teacher (blue bars) and illustrates the conclusions from the multilevel analyses that are discussed below.

- Relatedness to teacher: As hypothesized given the educational setting in the different conditions, Rel_Teacher is high in both the F2F and the hybrid-F2F setting, whereas Rel_Teacher is low in the virtual and hybrid-remote setting. The reported Rel_Teacher was the highest in the hybrid-F2F setting.

- Relatedness to peers: It was found that students' Rel_Peers was the highest in the F2F setting. A significant difference was found comparing with the hybrid-F2F setting and with the virtual. Rel_peers in these two settings did not significantly differ from each other, but was significantly higher than the hybrid-remote setting, which turned out to be the worst condition in terms of Rel_Peers. 
- Intrinsic motivation: IM was the lowest in the hybrid-remote setting, compared to the three other settings.

These quantitative results are in line with the qualitative results as both the teacher and the students mentioned that the hybrid sessions were the most puzzling to follow on the one hand and to teach on the other hand.

The teacher in that sense expressed the following:

"It is not always easy to divide the attention between the F2F students and the remote students."

On the students' side, one of the obstacles which were mentioned is that the F2F students had to use the microphone when reacting orally to make sure that the remote students could hear them. They expressed that this did not feel naturally. A student also indicated that he often turned his head during the lesson to see the faces of his peers on the screens in the back. Another student also explicitly mentioned to feel a distance from their peers and the teacher and expressed that it was like watching a movie without feeling real contact. This student mentioned that is was boring and weird to be separated from the others in the hybrid-remote setting. Students also indicated that following the lecture virtually was more tiring and that this kind of learning is only suitable for certain courses with a maximum of 2 hours a day. Yet, students mentioned that the available chat box might have helped in establishing some sort of connectedness with their peers. Overall, most students did also mention that they experienced the remote learning positively and stressed that they were surprised about the possibilities of the new technology and students found it easy to use.

This positive evaluation was also shared by the teacher. During the final interview, conducted at the end of the experiment, the teacher expressed his enthusiasm about this educational experiment and mentioned that the experience exceeded his expectations. He stated this as following:

\footnotetext{
"I thought that teaching to virtual students would have been very artificial and weird, but this was not the case at all. I had the feeling that my students were very close to me and could see their faces and expression quite good;... I could easily interact with them as I do in a normal class setting and I had the feeling my students were very attentive."
}

The teacher also stated that the educational setting had not influenced his style of teaching. He mentioned that he could easily start a dialogue and stated that the students who were most interacting are the same as in normal F2F classes. Yet, he expressed that he missed his traditional white board. Although there is a white board function in the platform, the teacher did not use it because he was not used to it and was afraid that it would not work. 


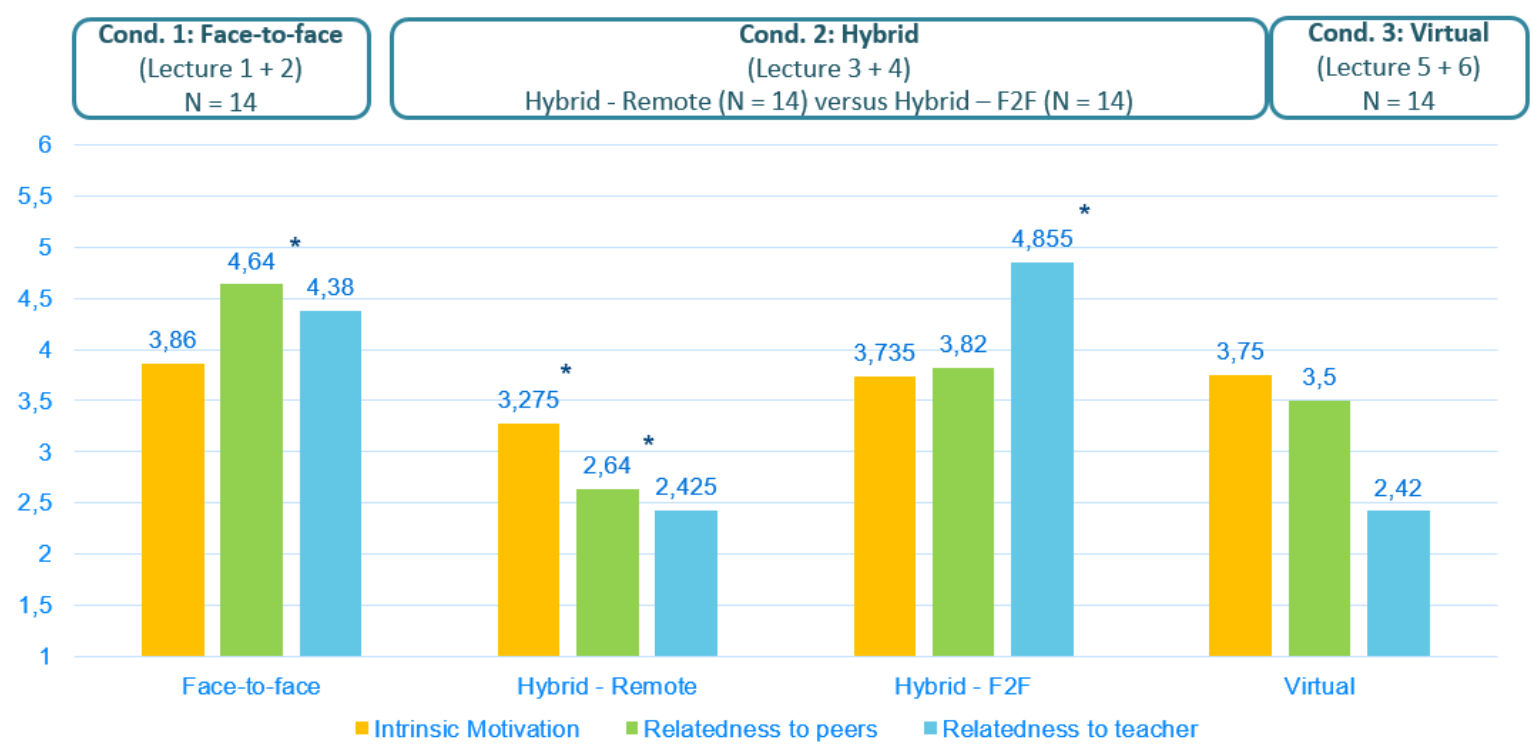

Figure 4. Post-test results of the subscales IM and relatedness in the three learning conditions.

Figure 5 presents the results of the engagement pop-up visualizing how affective engagement of the 14 students evolved during the six lectures. The Y-axis presents students' answers on the question "How engaged are you now?" which students could answer on a slider with a maximum value of 2 - very engaged and a minimum of 0 - very disengaged. A score of 1 represents a neutral engagement state. The slider always started at the neutral score. The Xaxis presents the time point on which the pop-up was received. Further analysis of these digital self-reports confirmed the findings from the self-reports at the end of the course. The results indicated that engagement scores were the highest when all students were physically present in the classroom and were the lowest for remote students in the hybrid setting. 

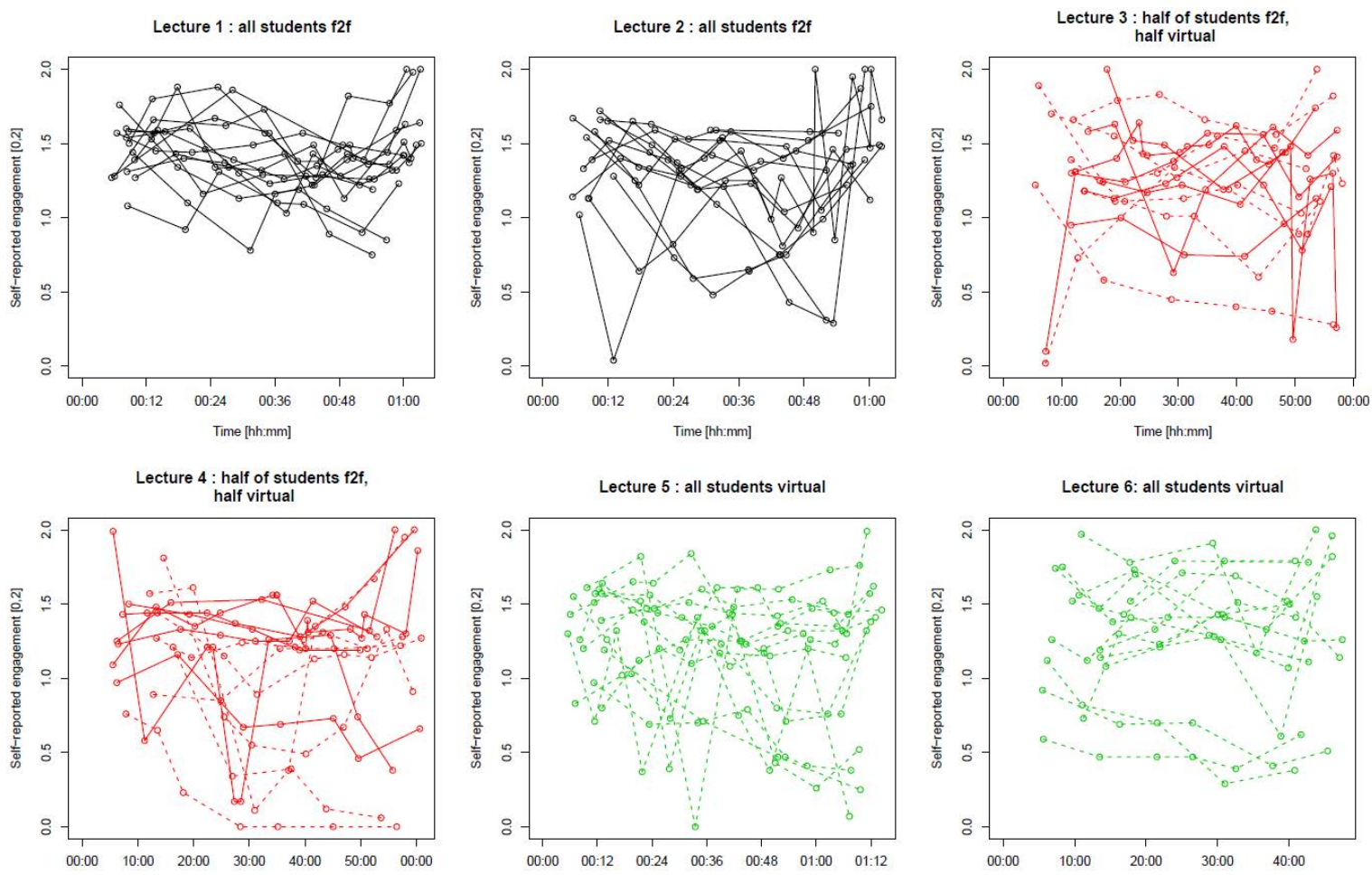

Figure 5. Results of the engagement pop-up. Solid lines apply to students who were following the lecture F2F;

dashed lines apply to students who were following the lecture remotely.

\section{Conclusion}

Based on previous literature and more specifically based on the self-determination theory, this study hypothesized that the more related students feel with their peers and their teacher, the better IM in learning is supported (Hutchinson et al., 2017). It was hypothesized that students would be most motivated in the F2F setting and least motivated in the remote setting. This hypothesis is partly confirmed, as the lowest IM was found in the hybrid-remote setting. However, no significant difference was found between the pure F2F and virtual setting. If students were asked which educational setting they prefer, most students still prefer the F2F sessions, but we can conclude that both the teacher and the students were positive about the hybrid virtual classroom and approved the benefit that students are able to attend courses in a flexible way (Lakhal et al., 2017). Yet, our study shows that particularly the hybrid setting is challenging for the remote students as it combines the F2F and remote perspective. These findings confirm previous findings of Ramsey, Evans, and Levy (2016) that remote learners indeed feel a significant sense of distance between remote students and their teachers and face-to-face classmates. Future research should investigate how this connectivity can be approved by means of instructional interventions like collaborative breakout-sessions between F2F and remote students and interactive quizzes and polls. 


\section{References}

Cohen, L., Manion, L., \& Morrison, K. (2011). Research Methods in Education ( $7^{\text {th }}$ ed.). London: Routledge.

Deci, E. L., \& Ryan, R. M. (1985). The General Causality Orientations Scale - SelfDetermination in Personality. Journal of Research in Personality, 19(2), 109-134.

Dobbins, C., \& Denton, P. (2017). MyWallMate: An Investigation into the use of Mobile Technology in Enhancing Student Engagement. TechTrends, 61(6), 541-549. https://doi.org/10.1007/s11528-017-0188-y

Fredricks, J. A., Blumenfeld, P. C., \& Paris, A. H. (2004). School Engagement: Potential of the Concept, State of the Evidence. Review of Educational Research, 74(1), 59-109. https://doi.org/10.3102/00346543074001059

Gobert, J. D., Baker, R. S., \& Wixon, M. B. (2015). Operationalizing and Detecting Disengagement Within Online Science Microworlds. Educational Psychologist, 50(1), $43-$ 57. https://doi.org/10.1017/CBO9781107415324.004

Hutchinson, S. L., Lauckner, H., Meisner, B. A., Gallant, K., \& Silversides, K. (2017). Fostering self-determination and sense of belonging through leisure education: reflections on the Steps to Connect program. Loisir et Société / Society and Leisure, 40(3), 360-376. doi: 10.1080/07053436.2017.1378503

Lakhal, S., De Sherbrooke, U., \& Bateman, D. (2017). Blended Synchronous Delivery Mode in Graduate Programs: A Literature Review and its Implementation in the Master Teacher Program. Collected Essays on Learning and Teaching, 47-60. https://doi.org/10.22329/celt.v10i0.4747

Niemiec, C. P., \& Ryan, R. M. (2009). Autonomy, competence, and relatedness in the classroom: Applying self-determination theory to educational practice. Theory and Research in Education, 7(2), 133-144. https://doi.org/10.1177/1477878509104318

Raes, A., \& Schellens, T. (2015). Unraveling the motivational effects and challenges of webbased collaborative inquiry learning across different groups of learners. Educational Technology Research and Development, 63(3), 405-430. https://doi.org/10.1007/s11423015-9381-x

Ramsey, D., Evans, J., \& Levy, M. (2016). Preserving the Seminar Experience. Journal of Political Science Education, 12(3), 256-267. https://doi.org/10.1080/15512169.2015.1077713

Scherer, K. R. (2005). What are emotions? And how can they be measured? Social Science Information, 44, 693-727.

Vansteenkiste, M., Sierens, E., Soenens, B., Luyckx, K., \& Lens, W. (2009). Motivational Profiles from a Self-Determination Perspective: The Quality of Motivation Matters. Journal of Educational Psychology, 101(3), 671-688. doi: 10.1037/A0015083 
Weitze, C. L. (2015). Pedagogical innovation in teacher teams: An organisational learning design model for continuous competence development. In A. Jefferies, \& M. Cubric (Eds.), Proceedings of 14 ${ }^{\text {th }}$ European Conference on e-Learning ECEL-2015 (pp. 629-638). Reading, UK: Academic Conferences and Publishing International.

\section{Acknowledgements}

This research is partially funded by imec through ICON LECTURE+. LECTURE+ is a project realized in collaboration with imec, with Barco, Televic Education and Limecraft as project partners and with project support from VLAIO. 